\title{
Parent material and pedogenic thresholds: observations and a simple model
}

\author{
Peter Vitousek (1D) Jean L. Dixon • Oliver A. Chadwick
}

Received: 24 May 2016/ Accepted: 21 September 2016/Published online: 8 October 2016

(C) The Author(s) 2016. This article is published with open access at Springerlink.com

\begin{abstract}
Pedogenic thresholds, where multiple soil properties vary substantially and coherently in a narrow portion of a broad environmental gradient, are well-described on basaltic soils in Hawaii. One such threshold occurs along climate gradients where primary minerals virtually disappear, base saturation decreases sharply, and aluminum is mobilized within a narrow range of increasing rainfall. A recent study that evaluated thresholds along a climate gradient of nonbasalt-derived soils on the South Island of New Zealand found that while base saturation declined steeply in a narrow range of rainfall on that gradient, the change was not coherent across soil properties; a substantial fraction of the $\mathrm{Ca}$ present in primary
\end{abstract}

Responsible Editor: Marc G. Kramer.

Electronic supplementary material The online version of this article (doi:10.1007/s10533-016-0249-x) contains supplementary material, which is available to authorized users.

P. Vitousek $(\square)$

Department of Biology, Stanford University, Stanford, CA 94305, USA

e-mail: vitousek@stanford.edu

J. L. Dixon

Department of Earth Sciences, Montana State University, Bozeman, MT 59715, USA

O. A. Chadwick

Department of Geography, University of California, Santa

Barbara, Santa Barbara, CA 93106, USA minerals (40-60\%) remained through the highestrainfall sites ((Dixon et al. in J Geophys Res, doi: 10.1002/2016JF003864, 2016). We developed a simple model to explore potential mechanisms driving differences between basalt-derived and non-basalt soils. Incorporating a broader spectrum of mineral weathering rates (including some primary minerals that are highly recalcitrant to weathering) into simulated non-basalt than simulated basalt-derived soils (and accounting for the lower rates of evapotranspiration in New Zealand) was sufficient to simulate observed differences between these substrates. Further, we used the simple model to evaluate the consequences of rainfall variation in the short- (time step to time step) and long-term (a change in rainfall after 50,000 time steps). Results of these analyses demonstrated that year-to-year variation in rainfall could play an important role in controlling changes in the position of the pedogenic threshold during soil development.

Keywords Hawaiian Islands · Lithology · Mineral weathering $\cdot$ New Zealand $\cdot$ Pedogenic thresholds

\section{Introduction}

Basalt-derived soils in the Hawaiian Islands do not change linearly in response to extrinsic differences in environmental forcing such as rainfall; rather their response is characterized by "pedogenic thresholds" 
that represent abrupt and/or non-linear (but predictable) changes in soil properties and processes (Chadwick and Chorover 2001). For example; Chadwick et al. (2003) demonstrated that base (nonhydrolyzing) cation saturation of soil exchange sites dropped from high values to $5 \%$ or less (to $1 \mathrm{~m}$ depth) across a narrow range of precipitation values (between 1700 and $1900 \mathrm{~mm}$ of rainfall on a climate gradient from 250 to $3000 \mathrm{~mm} /$ year, using rainfall from Giambelluca et al. 2012). This change was caused by depletion of primary minerals in higher rainfall sites, such that mineral weathering could not buffer atmospheric and biological acidity there. In support of this explanation, $\mathrm{Sr}$ isotopes $\left({ }^{87} \mathrm{Sr} /{ }^{86} \mathrm{Sr}\right)$ also changed abruptly at this threshold, from values characteristic of Hawaiian basalt in drier sites to those characteristic of marine aerosol in wetter sites (Stewart et al. 2001; Chadwick et al. 2003).

A similar pedogenic threshold has been observed along rainfall gradients on both younger (Lincoln et al. 2014) and older (Vitousek and Chadwick 2013) substrates in Hawaii, although this threshold occurs at differing average rainfall on the different-aged substrates. Additional thresholds associated with soil anaerobiosis (Chadwick and Chorover 2001; Miller et al. 2001; Thompson et al. 2011) and with biological uplift of plant macronutrients (Vitousek et al. 2004) have been described as well.

Pedogenic thresholds are well documented on basalt-derived soils, but there is evidence for their importance on other substrates as well (Muhs 1984). For example, Dahlgren et al. (1997) analyzed soil properties along a climate gradient in the Sierra Nevada Range and identified a relatively narrow zone where primary mineral weathering and clay mineral formation were enhanced greatly by a favorable combination of temperature and rainfall. Ewing et al. (2006) documented a strong shift from accumulation of atmospheric salts in the hyperarid core of the Atacama Desert to in situ mineral weathering and pedogenic carbonate formation on the wetter, arid fringes of the desert. Additional thresholds have been described along regional scale ecotones such as transitions from tundra to boreal forest (Ugolini and Spaltenstein 1992). At a global scale, a water-balance driven threshold in soil $\mathrm{pH}$ has been documented using a 60,000 pedon database (Slessarev et al. in press).

While climate-driven pedogenic thresholds occur in soils developed in diverse substrates, there is reason to anticipate that the threshold associated with mineral depletion in basalt-derived soils could differ fundamentally from thresholds in non-basalt soils. Most primary minerals present in basalt weather at similar (and relatively rapid) rates, in comparison with the much wider range of primary minerals present in most other lithologies.

In this paper, we use a simple "toy" model and observations from basaltic soils in Hawaii (Chadwick et al. 2003; Vitousek and Chadwick 2013) and nonbasalt soils in New Zealand (Dixon et al. 2016) to evaluate the nature, dynamics, and underlying mechanisms driving the mineral depletion pedogenic threshold on basalt-derived and one type of non-basalt soil. Further, we use the model to explore the importance of rainfall variation in shaping changes in the position of this pedogenic threshold.

\section{Methods}

Weathering model

We developed a simple "toy" model (defined as a simplified set of objects and equations that can be used to understand a mechanism) to explore the influence of parent material and of rainfall variability on weathering, leaching, and the dynamics of the mineral depletion pedogenic threshold. The model is written in Matlab (Mathworks Inc.), and is available in on-line supplementary material; it simulates the release of a soluble weathering product from primary minerals, its concentration in soil, and its loss via leaching. Just one soil layer is considered; water enters via precipitation, and is lost via evapotranspiration (considered to have a maximum value per time step, progressively reduced by water contents below the water holding capacity of the soil) and via leaching (calculated as all water that remains in the soil after evapotranspiration, in excess of a fixed water holding capacity). The soluble product (conceptually, a soluble cation like calcium) is released from minerals via weathering; it occurs in soluble form in the soil, and is leached from the soil in proportion its concentration and to the fraction of total soil water (after precipitation and evapotranspiration, before leaching) that is leached from the soil.

We assume that simulated parent materials are made up of three classes of minerals that contain equal amounts of the element of interest and that differ in 
how rapidly they weather (chemically). There are two components to differences in weathering rates of different minerals-solubility (the equilibrium concentration of weathering products in solution) and kinetics (differences in the rate at which minerals break down, at a given disequilibrium solution concentration of weathering products). We model both of these components-and initially we treat them as correlated, so that a sparingly soluble mineral will also have a slow kinetic component to its overall weathering rate. We calculate weathering of each class of minerals in each substrate as:

$$
\begin{aligned}
& \text { WeatherCa } a_{\mathrm{x}}=\text { weathercoeff }_{\mathrm{x}} \times(\text { soilwater } / \mathrm{WHC}) \\
& \times\left(\text { MaxCaconc }_{\mathrm{x}}-\text { Caconc }\right),
\end{aligned}
$$

where weatherCa $\mathrm{a}_{\mathrm{x}}$ is the release of soluble cation from mineral class $x$ (of the three making up each substrate), weathercoeff ${ }_{x}$ is the kinetic coefficient for that class of mineral in that parent material, soilwater/WHC is the soil water content as a fraction of water holding capacity, and (MaxCaconc ${ }_{\mathrm{x}}-$ Caconc) is the disequilibrium between the solution concentration of weathering product that inhibits further weathering of mineral class $\mathrm{x}$ (with the same values for MaxCaconc for the different minerals as for the kinetic coefficients) and the current solution concentration of that weathering product (Caconc). We assume that the concentration of the weathering product in soil represents "available" cations in the soil; in practice these cations would be in equilibrium with exchangeable cations. Because we set the initial quantity of cations in primary minerals at the beginning of a simulation, we can also determine the proportion of parent material cations remaining in the soil at any time in a simulation. The model does not account for erosion and uplift (e.g., Hilley et al. 2010), and so does not simulate steady-state dynamics; it could be modified to do so, but in this form we believe it represents the dynamics of soils on sampling locations that are little-affected by erosion.

Initially, we chose kinetic coefficients and solubilities to simulate the relatively rapid and consistent weathering of minerals in basalt by assuming that the three classes of minerals simulated vary in both solubility and kinetics at a ratio of 1:0.5:0.2. As reported below, the use of these coefficients yielded a coherent threshold in which both simulated "available" cations and simulated "cations remaining in mineral form" were depleted in simulated highrainfall sites by 100,000 time steps of simulation-a pattern consistent with field observations on basalt soils (Chadwick et al. 2003).

We then explored a range of coefficients and solubilities for the more recalcitrant minerals, and found that at values $>\sim 0.1$ for the second mineral, simulated pools of this mineral largely disappeared by 100,000 time steps of simulation. For the third (most recalcitrant) mineral, there was little simulated weathering in 100,000 time steps at kinetic coefficients/solubilities $<\sim 0.05$. Based on these observations, we chose to use kinetic coefficients/solubilities for non-basalt parent material that vary by 1:0.1:0.01; we describe the implications of this choice in "Discussion" Section.

We also use this toy model to evaluate the effects of rainfall variation on weathering, leaching, and the dynamics of the mineral depletion pedogenic threshold. For runs without time step to time step variation in rainfall, we vary rainfall per time step from 1 to 30 units in increments of 1 , set evapotranspiration to a consistent value (initially 10), and run the model at each simulated rainfall over several thousand to several million time steps - tracking the influence of variation in average rainfall on simulated soluble cation concentrations in soil and on the simulated fraction of parent material cations remaining within the soil. To introduce higherfrequency rainfall variation, we continue to evaluate average rainfall from $\sim 1$ to $\sim 30$ units-but we calculate the rainfall in each time step stochastically, as:

$$
\begin{aligned}
\text { Rainfall }= & \text { Indexrainfall } \\
& +(\text { Indexrainfall } \times(10 \times \text { RND }-6.5)),
\end{aligned}
$$

where Rainfall is the simulated rainfall at each time step, Indexrainfall varies systematically from 1 to 30 units, RND is a random number evenly distributed between 0 and 1, and 6.5 is an empirical value selected to make the value of Rainfall averaged over many time steps similar to Indexrainfall. This yields highly variable rainfall per time step; where simulated rainfall is $<0$, we set rainfall for that time step to 0.001 .

Finally, we explore the reversibility of the cation depletion pedogenic threshold by reducing the mean rainfall in the midst of a run. For this analysis, we run the model for 40,000 time steps at a constant rainfall level $50 \%$ above that at which a threshold developsand then cut rainfall in half and run the model for another 20,000 time steps. 
Field sites

We compared outputs from the toy model to soil properties measured on climate gradients of basaltderived soils in Hawaii and of non-basalt-derived soils in New Zealand. The Hawaiian climate gradient is described in Chadwick et al. (2003) and Vitousek and Chadwick (2013); our comparisons are to Vitousek and Chadwick's Hawi basalt sequence on 150 kyr old substrate, along which annual precipitation reaches from $\sim 285$ to $\sim 3250 \mathrm{~mm} /$ year in soils that are largely derived from tephra. The most important parent minerals along this gradient are basaltic glass, plagioclase, olivine and pyroxene (Spengler and Garcia, 1988). Results for the New Zealand climate gradient are described in Dixon et al. (2016); this sequence was expanded from a 4-point gradient characterized by Webb et al. (1986) to a 28-site gradient that includes sites with mean annual rainfalls from $\sim 400$ to $\sim 4700 \mathrm{~mm} /$ year (Kerr 2009). This climate gradient covers $60 \mathrm{~km}$ in Waitaki Valley, from just south of Aoraki/Mt Cook southeastward along Lake Pukaki into the rain shadow of the Southern Alps. Soils are developed in wind-derived loess deposited on well-mapped moraines of known age from 12.6 to $19.7 \mathrm{kyr}$ (Schaefer et al. 2006; Putnam et al. 2010; Barrell et al. 2011); we sampled loess deposited on moraines and outwash from the preHolocene Last Glacial Maximum (LGM) (Tekapo Formation) and from a relatively old Post-LGM moraine (Birch Hill Formation). The loess and its underlying till are carbonate-poor and derived from greywacke and argillite bedrock of the Torlesse Supergroup, which is a component of uplifted Mesozoic turbidite sequences (Eden and Hammond 2003; Raeside 1964). These parent rocks yield a loess mineral assemblage including quartz, K-feldspar, muscovite, plagioclase, and minor chlorite (Spörli and Lillie 1974; Webb et al. 1986).

Field sampling

Hawaii soils were obtained as integrated soil samples from the surface to $30 \mathrm{~cm}$ depth in $>150$ locations on the 150 kyr Hawi substrate (Vitousek and Chadwick 2013); soils were also sampled by horizon to depths of up to $5 \mathrm{~m}$ (using a backhoe) in 13 sites along the gradient (Porder and Chadwick 2009). In New Zealand, we sampled soils developed in thin $(\sim 1 \mathrm{~m})$ loess deposits on moraines and outwash as described in Dixon et al. (2016). All sample sites were located on the flat upper surface of moraines and abandoned outwash fans. Soil was collected from each of 28 profiles by integrated sampling every $10 \mathrm{~cm}$ from the soil surface to contact with coarse glacial till. The sampled soils range from about 40 to $150 \mathrm{~cm}$ in depth with most being 60 to $70 \mathrm{~cm}$. Here we compare $30 \mathrm{~cm}$ depth-integrated samples from Hawaii with bulkdensity-weighted integrations of the top three $10-\mathrm{cm}$ samples from New Zealand. Results for the full soil profiles are in Dixon et al. (2016) for New Zealand, and in Chadwick et al. (2003), Porder et al. (2007), and Vitousek and Chadwick (2013) for Hawaii.

Analyses

Both New Zealand and Hawaii soils were air dried and sieved to remove the coarse $>2 \mathrm{~mm}$ fraction. Exchangeable cations, cation exchange capacity, and $\mathrm{pH}$ were measured at UCSB; soils were extracted by $\mathrm{NH}_{4} \mathrm{OAC}$ buffered at $\mathrm{pH} 7$ for exchangeable cation and cation exchange capacity analyses. Bulk soil elemental concentrations were measured with X-ray fluorescence by ALS Chemex following lithium borate fusion. To calculate gains and losses of elements, we indexed total element inventories in soils to the quantities present in parent material using a high field-strength (relatively immobile) index element (Chadwick et al. 1990). The percentage of an element $X$ remaining in soil relative to parent material $\left(\mathrm{ER}_{\mathrm{x}}\right)$ was calculated as:

$\mathrm{ER}_{\mathrm{x}}=100 \times\left(\mathrm{X}_{\mathrm{s}} / \mathrm{IE}_{\mathrm{s}}\right) /\left(\mathrm{X}_{\mathrm{pm}} / \mathrm{IE}_{\mathrm{pm}}\right)$

where $X_{s}$ and $X_{p m}$ are the quantity of element $X$ in soil and parent material respectively, and $\mathrm{IE}_{\mathrm{s}}$ and $\mathrm{IE}_{\mathrm{pm}}$ are the quantity of the index element. We used niobium as the index element for Hawaiian soils, as Kurtz et al. (2000) demonstrated (with Ta) it is the least mobile element, while Ti was used as the index element in New Zealand (Dixon et al. 2016).

\section{Results}

Field

We focus here on two soil properties that are relevant to the mineral depletion threshold identified by Chadwick and Chorover (2001) and Chadwick et al. 
(2003), and that are comparable to outputs of the toy model - base saturation, and the proportion of calcium remaining in the soil (relative to the calcium present in parent material). The former is a measure of the abundance of potentially mobile (and biologically available) cations in the soil, while the latter represents calcium that is available for release into the soil.

Base saturation in New Zealand soils from the Lake Pukaki sequence declined rapidly with increasing rainfall, from $\sim 70 \%$ in the driest sites to $<20 \%$ in most sites with $>800 \mathrm{~mm}$ annual rainfall. Base saturation in soils from the Hawi rainfall gradient in Hawaii also declined with increasing rainfall, though at higher levels of rainfall; base saturation was $\sim 70 \%$ at $1300 \mathrm{~mm}$ annual precipitation, and declined to $<20 \%$ (to $30 \mathrm{~cm}$ ) above $2100 \mathrm{~mm} /$ year (Fig. 1a). In addition, Hawi soils receiving $<1000 \mathrm{~mm} /$ year precipitation had lower base saturation than slightly wetter sites, a pattern Vitousek and Chadwick (2013) ascribed to biological uplift of plant nutrients in sites with intermediate rainfall.

On the Lake Pukaki sequence, the fraction of calcium remaining in soil initially declined from nearly 100 to $\sim 60 \%$ with increasing rainfall from $\sim 400$ to $\sim 800 \mathrm{~mm} / \mathrm{year}$. This fraction ranged from $\sim 40$ to $60 \%$ into the wettest sites. In contrast, $\mathrm{Ca}$ remaining in the Hawi tephra declined from $\sim 40$ to $80 \%$ in sites receiving $<1300 \mathrm{~mm} /$ year to $<10 \%$ in sites receiving $>2100 \mathrm{~mm} /$ year (Fig. 1b). Again, soils from sites receiving $<1000 \mathrm{~mm} /$ year had lower $\mathrm{Ca}$ remaining than sites receiving $1300 \mathrm{~mm} /$ year on the Hawi gradient, reflecting a stronger imprint of biological uplift in the moderate-rainfall soils (Vitousek and Chadwick 2013).

\section{Model—parent material comparison}

We compared simulated basalt and non-basalt parent material along rainfall gradients by evaluating the simulated concentrations of soluble cations present in the soil (after weathering and before leaching at that time step) and the simulated proportion of cations from parent material that remain in soil. The former is not directly comparable to base saturation-cation exchange is not considered in the model-but it does represent the pool of cations that would be in equilibrium with exchangeable cations. The latter is comparable to calcium remaining in soils in the field. Comparing basalt and non-basalt parent material (as characterized in Methods) for the same number of time steps $(100,000)$ and the same potential evapotranspiration (10 units)) yields the results in Fig. 2. Simulated pools of soluble cations decline at only slightly lower rainfall on non-basalt versus basalt (from 5 to 6 units on non-basalt and from 5 to 8 units on basalt), and the decline in cations remaining begins at the same rainfall level in both - unlike observations in the field (Fig. 1). However, in basalt the simulated fraction of parent material cations remaining declines to near zero simultaneously with the decline in soluble cations, while in non-basalt $\sim 50 \%$ of simulated parent material cations are retained into the wettest conditions-much like observations in the field (Fig. 1).

Next, we explored the influence of the rate of potential evapotranspiration (ET), which is much greater in the subtropical Hawaiian environment than in cool temperate South Island, New Zealand. Comparing simulations with the same levels of rainfall but with potential ET for the simulated basalt substrate twice that for the simulated non-basalt substrate (10 units versus 5 units) yielded the results in Fig. 3. The lower potential ET for simulated non-basalt caused an increase in leaching intensity that shifted the decline in soluble cations to a drier position on the modeled rainfall gradient - and the pattern in Fig. 3 is comparable to that observed in the field (Fig. 1), except for the lack of a signal for biological uplift (which was not simulated in the model).

Model—rainfall variation

Empirical research on basalt soils in Hawaii has demonstrated that the pedogenic threshold associated with mineral depletion shifts to drier sites on substantially older parent material (Vitousek and Chadwick 2013). However, the current model that represents this threshold (Chadwick et al. 2003) equilibrates with average rainfall and does not yield an ongoing shift in the threshold over time. Here we use the toy model to explore how rainfall variability could contribute to the dynamism of this threshold on long time scales. For this analysis, we ran the model (for simulated basalt substrates) with constant rainfall at the average value for each rainfall level simulated, and with rainfall that varied stochastically from time step to time step as described in Methods, for 100,000 versus 1,000,000 time steps. The results of this analysis are summarized in Fig. 4. At constant rainfall, increasing the number 
Fig. 1 Variation in base saturation (a) and the proportion of calcium remaining from parent material (b) along rainfall gradients in Hawaii and New Zealand. The Hawi rainfall gradient on Hawaiian basalt is shown with hollow symbols (data from Vitousek and Chadwick 2013), while the Lake Pukaki rainfall gradient on greywackederived loess in New Zealand is shown with solid symbols (data from Dixon et al. 2016)

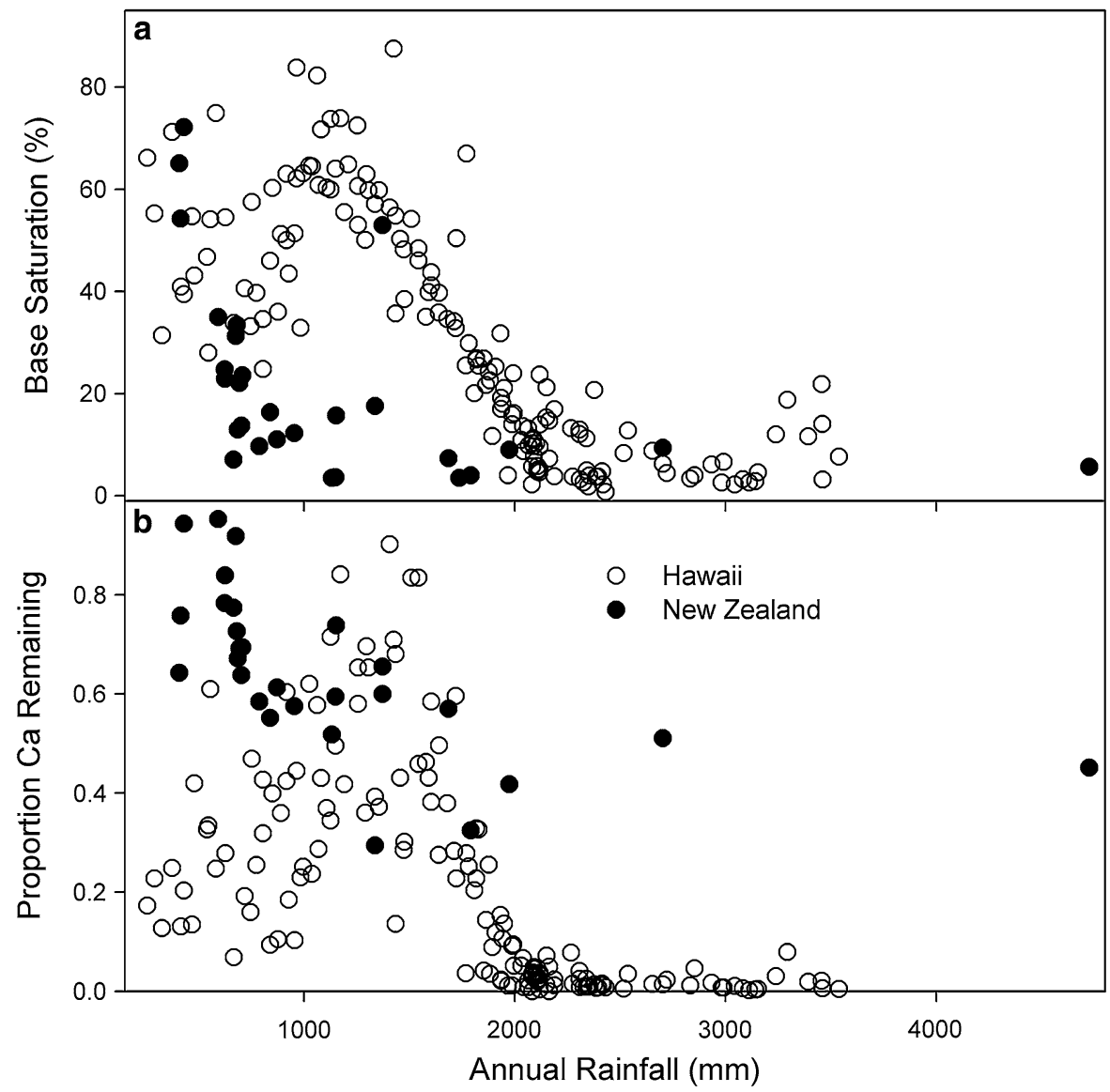

of time steps resulted in little change in either simulated soluble cations or simulated cations remaining; the only difference occurred just above the rainfall threshold, where some of the most recalcitrant mineral remained (and contributed to a relatively low concentration of cation in solution) after 100,000 but not 1,000,000 time steps (Fig. 4a). With stochastic variation in annual rainfall, the threshold shifted to a drier position on the gradient after 100,000 time steps-and it continued to shift to drier sites from 100,000 to 1,000,000 time steps (Fig. 4b).

Finally, we use the model to explore the consequences of a change in average rainfall on simulated soluble cations. Because the decline with increasing rainfall in simulated cation concentrations on basalt substrates is coincident with the depletion of cations remaining in parent material, the threshold should represent an irreversible change even if average rainfall on a depleted site decreases to a level below the threshold. However, a relatively large fraction of cations from simulated non-basalt parent material remains in the soil under these conditions. We used the model to test whether a decrease in rainfall of a magnitude similar to rainfall variation associated with glacial-interglacial cycles in Hawaii (Hotchkiss et al. 2000) could lead to a substantial increase in simulated cation concentrations (and so possibly a rejuvenation of soil fertility in depleted sites). This analysis is summarized in Fig. 5; as anticipated, soluble cation concentrations on simulated basalt did not increase when simulated average rainfall decreased. When both solubility and kinetic controls on mineral weathering (described in Methods) were in place, simulated nonbasalt substrates also did not respond to decreased rainfall (Fig. 5a) - and where only solubility controls were operative, cation concentrations still did not respond to decreased rainfall on simulated non-basalt substrates. However, when only kinetic controls operated, the model yielded a substantial increase in simulated cation concentration following a decrease in average rainfall on simulated non-basalt (though not basalt) substrate (Fig. 5b). 


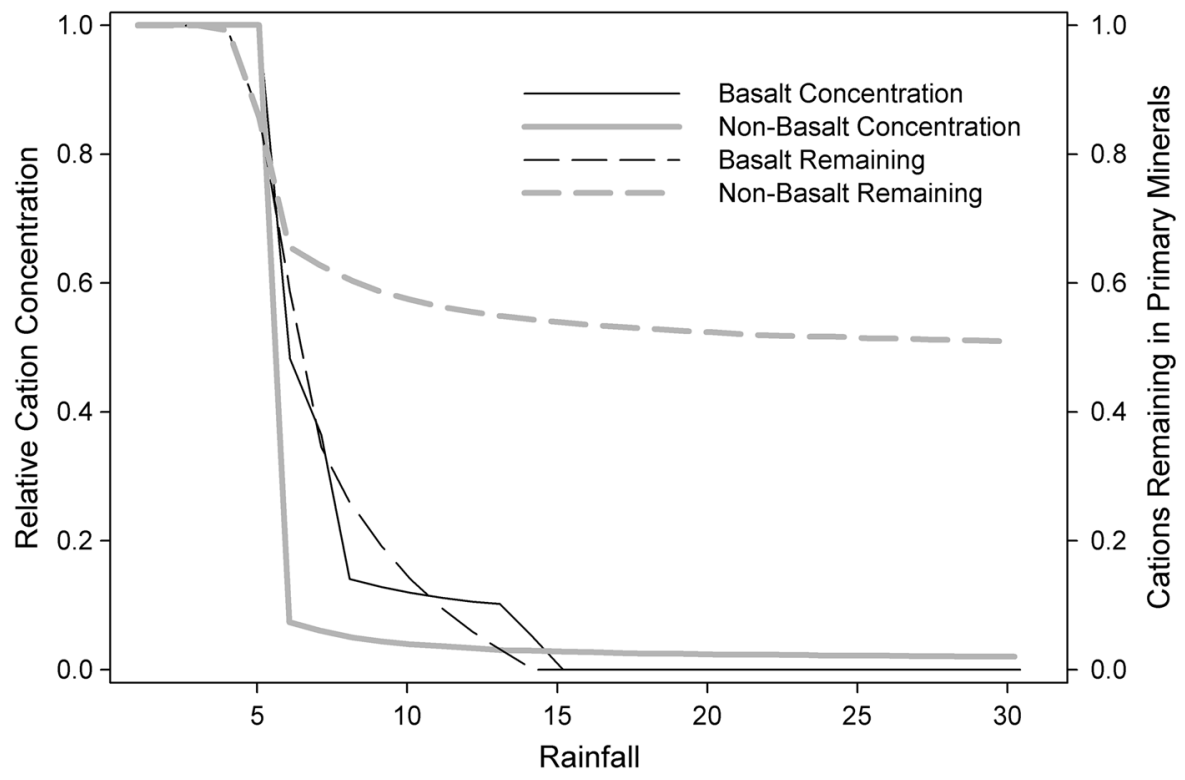

Fig. 2 Model output for the concentration of available cations in soil (solid lines) and the proportion of cations remaining from parent material (dashed lines) for simulated basalt-derived soils (thin black lines) and simulated non-basalt soils (thick grey lines) after 100,000 time steps along a rainfall gradient. Potential evapotranspiration and other conditions were identical for basalt and non-basalt, except for the spectrum of potential rates of mineral weathering. Simulated rainfall incorporated stochastic variation among time steps
Fig. 3 Model output for the concentration of available cations in soil (solid lines) and the proportion of cations remaining from parent material (dashed lines) for simulated basalt-derived soils (thin black lines) and simulated non-basalt soils (thick grey lines) along a rainfall gradient. Potential evapotranspiration on nonbasalt was set to $50 \%$ of that on basalt, to represent the cool temperate versus subtropical climate of South Island New Zealand versus Hawaii; all other conditions as in Fig. 2

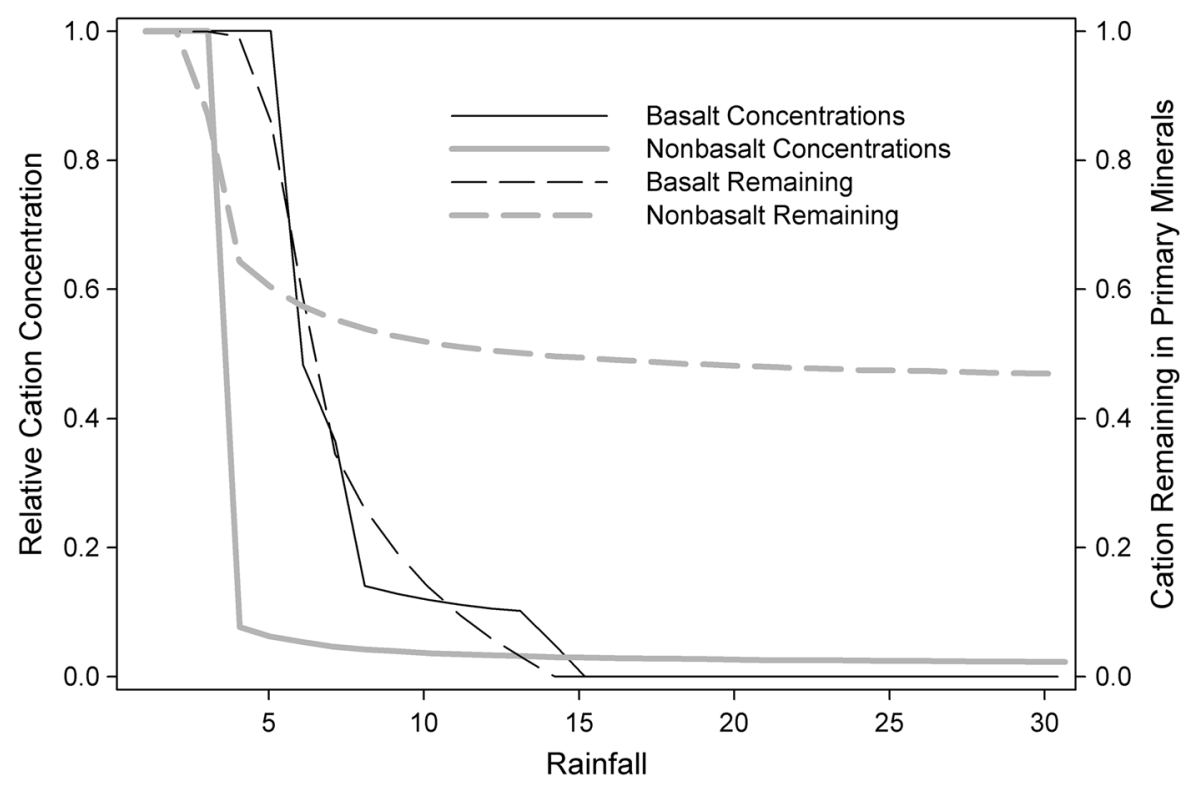

\section{Discussion}

Earlier research demonstrated (Chadwick and Chorover 2001; Chadwick et al. 2003; Vitousek and Chadwick 2013) that the pedogenic threshold associated with mineral depletion on basalt-derived soils in
Hawaii is both coherent and irreversible-coherent in that multiple soil properties change at the same small rainfall range across a broad gradient (Vitousek and Chadwick 2013), including both exchangeable cations (base saturation) and total cations remaining from parent material (Fig. 1), and irreversible because the 


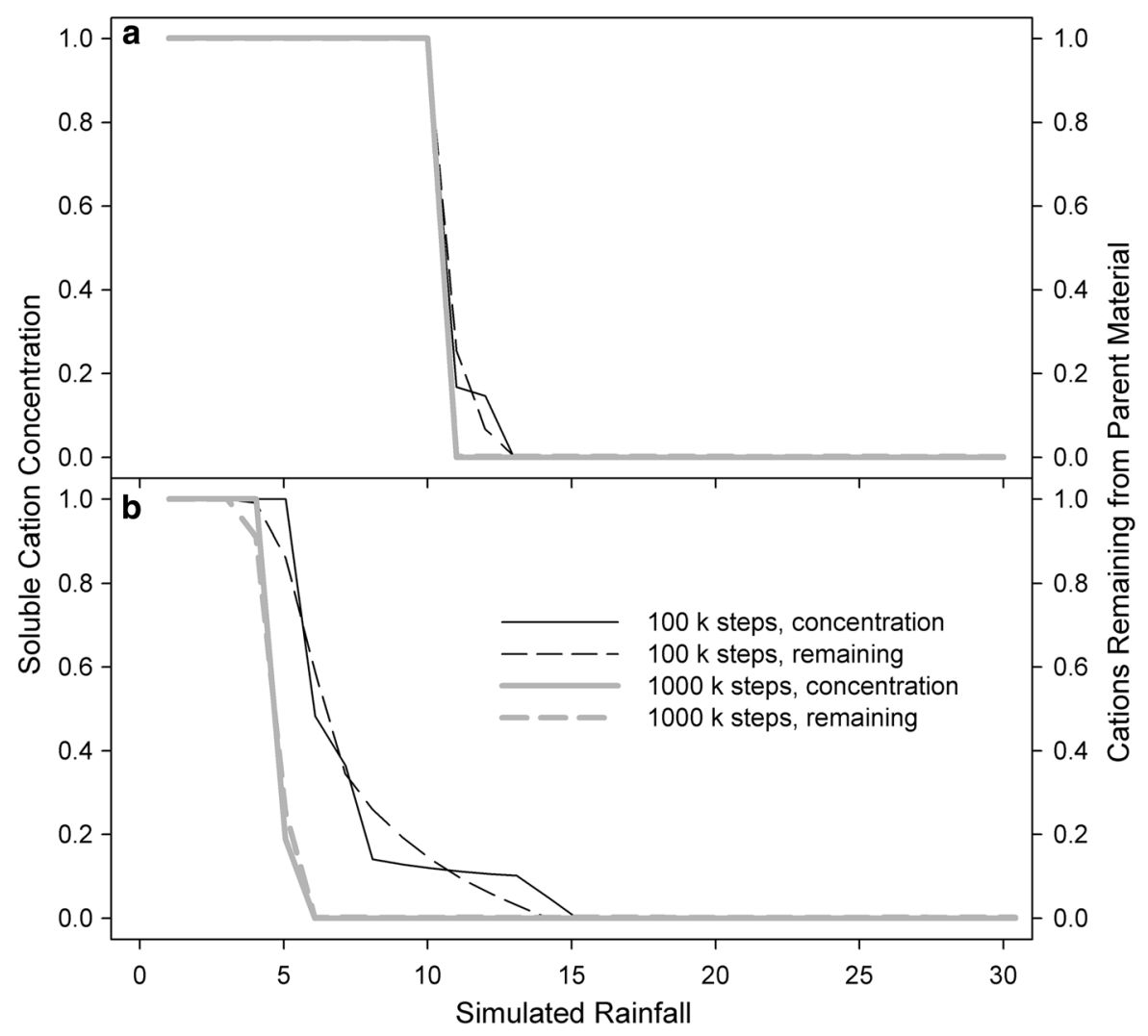

Fig. 4 Consequences of stochastic variation in simulated rainfall on simulated basalt substrate. a No time step to time step variation in rainfall. b Stochastic variation in rainfall among time steps; simulated as described in "Methods" section. Solid

depletion of cations remaining from primary minerals means that the low levels of available cations are permanent (absent fertilization, uplift, or dust deposition). Moist infertile soils now occur at rainfalls above the threshold, and if average rainfall declined substantially we would observe dry infertile soils there.

In contrast, while there is threshold behavior for exchangeable cations (base saturation) on the nonbasalt soils in New Zealand, demonstrated by a sharp decline in base saturation in a narrow portion of the broad gradient (Fig. 1) (Dixon et al. 2016), this threshold is more complex than the comparable threshold on Hawaiian basalt. While base saturation declines sharply to low levels between 400 and $800 \mathrm{~mm}$ annual precipitation, and the amount of calcium retained from parent material decreases across this same rainfall range, a substantial fraction (40-60\%) of the calcium originally present in parent material remains within the soils receiving more $800 \mathrm{~mm}$ precipitation. lines show simulated soluble cation concentrations, dashed lines show simulated total cations remaining within soil, relative to primary minerals. Thin black lines represent model runs of 100,000 time steps; thick grey lines 1,000,000 time steps

We used the toy model to explore possible mechanisms underlying the contrast between basalt-derived and non-basalt soils. The model is far from a complete description of soil formation and dynamics (cf Maher and Chamberlain 2014); rather, it is intended as a systematic way to explore the logical consequences of a relatively narrow range of (rapid) rates of weathering among primary minerals in basalt versus a broader range (including some with much lower rates) of weathering among primary minerals in non-basalt substrate. If model and observational results did not align qualitatively, we would conclude that the mechanism embedded in the model could not drive the observed pattern.

In this case, results of this simple model and observations agreed well (Figs. 1, 3), when we accounted for the lower rate of potential evapotranspiration in cool temperate New Zealand versus subtropical Hawaii. Very simple assumptions about variation in weathering rates among minerals suffice 


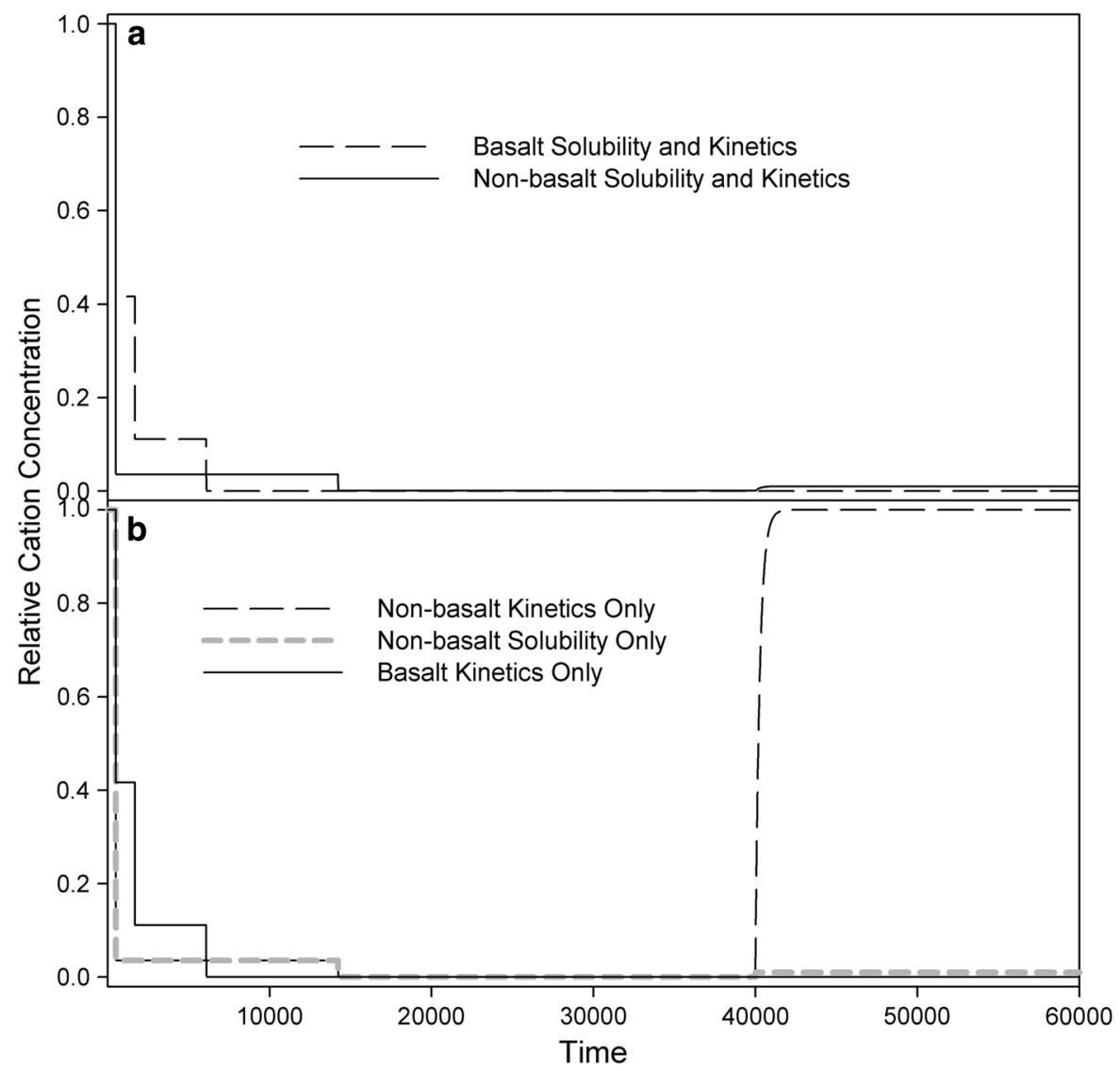

Fig. 5 Time course of simulated soluble cation concentrations during runs that start with rainfall sufficient to deplete cations, then switch to lower rainfall (insufficient to deplete cations) after 40,000 time steps, at which point cations have been depleted. a Both solubility and kinetic controls on weathering are utilized; solid line is non-basalt and dashed line is basalt.

to yield sharp thresholds in available cations on both simulated substrates, levels of primary mineral cations near zero in simulated basalt soils wetter than the threshold, and substantially higher levels of primary mineral cations remaining above the threshold in simulated non-basalt substrate-results that are consistent with field observations across broad climate gradients on each substrate.

The qualitative concordance between our simple model and field observations (Figs. 1, 3) is intriguing, but we must ask "how realistic is the range of weathering rates assumed in the model"? Quartz is present in the arkosic (non-basalt) substrate in New Zealand and absent from Hawaiian basalt; it weathers much more slowly than does any abundant mineral in basalt, but it contains essentially no calcium. b Solubility and kinetic controls are considered separately. Cation concentrations rebound to high levels only on non-basalt soils, and there only where only kinetic controls on weathering (and not solubility controls) are active. Simulated rainfall here does not incorporate stochastic variation among time steps

However, quartz can make more labile minerals inaccessible to weathering, in effect protecting them, and so can contribute to slower release of cations. Feldspars are the most recalcitrant minerals in Hawaiian basalt, and the most recalcitrant that contain substantial quantities of calcium on the New Zealand sequence-but different feldspars are important in each system. In basalt the dominant feldspar is plagioclase whereas in the arkosic materials it is a combination of plagioclase and more recalcitrant orthoclase ( $\mathrm{K}$ feldspar). Moreover, plagioclase itself is composed of a solid solution ranging from a pure $\mathrm{Ca}$ endmember (anorthite) and a $\mathrm{Na}$ endmember (albite). Solubility varies greatly and linearly between these two endmembers $\left(\log _{10} \mathrm{Ksp}=27.1\right.$ (at $25{ }^{\circ} \mathrm{C}$ ) for anorthite and 3.1 for albite), while between these 
endmembers are minerals such as oligoclase that has a mixture of $\mathrm{Ca}$ and $\mathrm{Na}$ and $\log _{10} \mathrm{Ksp}=8.3$ (Delany and Wolery 1989). In Hawaiian basalt about half the Ca resides in the anorthite end of the plagioclase series (with the rest in more soluble minerals such as volcanic glass and pyroxene), while in the arkosic loess in New Zealand, $\mathrm{Ca}$ is present (initially) in the more slowly weathering oligoclase to albite end of the plagioclase series.

In summary almost all of the Ca in Hawaiian basalt is hosted in more soluble minerals than is the majority of $\mathrm{Ca}$ in the New Zealand loess derived from arkosic rocks. Our selection of weathering rates mimics this fact without trying to be precise since there are many other controls on weathering including surface area, mineral protections by coatings and less soluble primary minerals (like the abundant quartz in the New Zealand sequence), and the heterogeneity of flow paths.

We also used the toy model to explore the influence of rainfall variation on two time scales. With constant rainfall (the same rainfall at every time step), a threshold change in available cations develops rapidly (within a few thousand time steps) in sufficiently wet sites on both basalt and non-basalt substrates, and this threshold then remains nearly fixed in place no matter how many time steps are added. However, when we incorporate stochastic time-step-to-time-step variation in rainfall to the model, the threshold migrates into drier conditions as more time steps are added (Fig. 4) -as we observe for thresholds on basalt substrates in the field in Hawaii (Vitousek and Chadwick 2013). This result is consistent with the suggestion that occasional high rainfall events determine properties of soils in the long term; indeed, the model may understate this effect, as maximum rainfall in a time step is constrained to be no more than $\sim 4.5 \times$ the mean rainfall per time step (see "Methods" section).

Finally, by running the model under a consistent rainfall regime, allowing available cations to become depleted, and then systematically decreasing rainfall to a level at which cations would not have become depleted (had the second, lower rainfall level persisted from the beginning of the simulation), we could evaluate the reversibility of cation depletion under changing climatic conditions. We found simulated cation depletion to be irreversible by simply by decreasing rainfall on simulated basalt substrates - as expected from the depletion of primary mineral cations on basalt (Figs. 1, 5); on simulated non-basalt, where relatively large quantities of cations remain in parent material after available cations are depleted, the reversibility of depletion depends on whether the weathering of relatively recalcitrant primary minerals is constrained by solubility (in which case the depletion is irreversible) or by kinetics (in which case available cations can accumulate in soils after the change in rainfall-Fig. 5). This result makes senseif weathering is constrained by low concentrations of available cations, then weathering can never provide high levels of those cations. However, we did not recognize the importance of the different mechanisms for constraining the weathering of recalcitrant minerals, until running the model.

Overall, evaluation of our field observations and simulations suggest that weathering-related pedogenic thresholds are widespread, although they may differ in fundamental ways in soils developed in different parent materials. These thresholds should be incorporated into considerations of climate constraints to ecosystem function and potential disruptions of ecosystems due to climate change.

Acknowledgments This research was supported by NSF Grants ETBC-1020791 and ETBC-1019640 to Stanford University and the University of California, Santa Barbara. JLD acknowledges support by MT-IOE award from NSF EPS1101342. We thank W.H. Schlesinger and S. Porder for helpful comments on an earlier draft.

Open Access This article is distributed under the terms of the Creative Commons Attribution 4.0 International License (http:// creativecommons.org/licenses/by/4.0/), which permits unrestricted use, distribution, and reproduction in any medium, provided you give appropriate credit to the original author(s) and the source, provide a link to the Creative Commons license, and indicate if changes were made.

\section{References}

Barrell DJA, Andersen BG, Denton GH (2011) Glacial geomorphology of the Central South Island, New Zealand. GNS Sci

Chadwick OA, Chorover J (2001) The chemistry of pedogenic thresholds. Geoderma 100:321-353

Chadwick OA, Brimhall GH, Hendricks DM (1990) From a black to a gray box: a mass balance interpretation of pedogenesis. Geomorphology 3:369-390

Chadwick OA, Gavenda RT, Kelly EF et al (2003) The impact of climate on the biogeochemical functioning of volcanic soils. Chem Geol 202:193-221 
Dahlgren RA, Boettinger JL, Huntington GL, Amundson RG (1997) Soil development along an elevational transect in the western Sierra Nevada, California. Geoderma 78:207-236

Delany JM, Wolery TJ (1989) The LLNL thermochemical database. Report UCRL-21658

Dixon JL, Chadwick OA, Vitousek PM (2016) Climate-driven thresholds for chemical weathering in post-glacial soils of New Zealand. J Geophys Res. doi:10.1002/2016JF003864

Eden DN, Hammond AP (2003) Dust accumulation in the New Zealand region since the last glacial maximum. Quat Sci Rev 22:2037-2052

Ewing SA, Sutter B, Amundson R et al (2006) A threshold in soil formation at Earth's arid-hyperarid transition. Geochim Cosmochim Acta 70:5293-5322

Giambelluca TW, Chen Q, Frazier AG et al (2012) Online rainfall atlas of Hawai'i. Bull Am Meteorol Soc. doi:10. 1175/BAMS-D-11-00228.1

Hilley GE, Chamberlain CP, Moon S et al (2010) Competition between erosion and reaction kinetics in controlling silicate-weathering rates. Earth Planet Sci Lett 293:191-199

Hotchkiss SC, Vitousek PM, Chadwick OA, Price JP (2000) Climate cycles, geomorphological change, and the interpretation of soil and ecosystem development. Ecosystems 3:522-533

Kerr T (2009) Precipitation distribution in the Lake Pukaki catchment, New Zealand. PhD, University of Canterbury.

Kurtz AC, Derry LA, Chadwick OA, Alfano MJ (2000) Refractory element mobility in volcanic soils. Geology 28:683-686

Lincoln NK, Vitousek PM, Chadwick OA (2014) Indicators of soil fertility and opportunities for precontact agriculture in Kona, Hawaii. Ecosphere. doi:10.1890/ES13-00328.1

Maher K, Chamberlain P (2014) Hydrologic regulation of chemical weathering and the geologic carbon cycle. Science 343:1502-1504

Miller AJ, Schuur EAG, Chadwick OA (2001) Redox control of phosphorus pools in montane forest soils in Hawaii. Geoderma 102:219-237

Muhs DR (1984) Intrinsic thresholds in soil systems. Phys Geogr 5:99-110

Porder S, Chadwick OA (2009) Climate and soil-age constraints on nutrient uplift and retention by plants. Ecology 90:623-636
Porder S, Hilley GE, Chadwick OA (2007) Chemical weathering, mass loss, and dust input across a climate by time matrix in the Hawaiian Islands. Earth Planet Sci Lett 258:414-427

Putnam AE, Denton GH, Schaefer JM et al (2010) Glacier advance in southern middle-latitudes during the Antarctic Cold Reversal. Nature Geosci 3:700-704

Raeside JD (1964) Loess deposits of the South Island, New Zealand, and soils formed on them. New Zealand J Geol Geophys 7:811-838

Schaefer JM, Denton GH, Barrell DJA et al (2006) Near-synchronous interhemispheric termination of the last glacial maximum in mid-latitudes. Science 312:1510-1513

Slessarev EW, Lin Y, Bingham NL, Johnson JE, Dai Y, Schimel JP, Chadwick OA (2016) Water balance creates a threshold in soil $\mathrm{pH}$ at the global scale. Nature (in press)

Stewart BW, Capo RC, Chadwick OA (2001) Effects of rainfall on weathering rate, base cation provenance, and $\mathrm{Sr}$ isotope composition of Hawaiian soils. Geochim Cosmochim Acta 65:1087-1099

Spengler SR, Garcia M (1988) Geochemistry of the Hawi lavas, Kohala Volcano, Hawaii. Contrib Mineral Petrol 99:90-104

Spörli KB, Lillie AR (1974) Geology of the Torlesse supergroup in the northern Ben Ohau Range, Canterbury. New Zealand J Geol Geophys 17:115-141

Thompson A, Rancourt DG, Chadwick OA, Chorover J (2011) Iron solid-phase differentiation along a redox gradient in basaltic soils. Geochim Cosmochim Acta 75:119-133

Ugolini FC, Spaltenstein H (1992) Pedosphere. Int Geophys 50:123-153

Vitousek PM, Chadwick OA (2013) Pedogenic thresholds and soil process domains in basalt-derived soils. Ecosystems. doi:10.1007/s10021-013-9690-z

Vitousek PM, Ladefoged TL, Kirch PV et al (2004) Agriculture, soils, and society in precontact Hawai'i. Science 304:1665-1669

Webb TH, Campbell AS, Fox FB (1986) Effect of rainfall on pedogenesis in a climosequence of soils near Lake Pukaki, New Zealand. N Z J Geol Geophys 29:323-334 